\title{
Ring-Expansion/Contraction Radical Crossover Reactions of Cyclic Alkoxyamines: A Mechanism for Ring Expansion-Controlled Radical Polymerization
}

\author{
Atsushi Narumi ${ }^{1, *}$, Tetsuya Kobayashi ${ }^{1}$, Masatsugu Yamada ${ }^{1}$, Wolfgang H. Binder ${ }^{2}$ (D), \\ Keigo Matsuda ${ }^{3}$ (D), Montaser Shaykoon Ahmed Shaykoon ${ }^{1}$, Kazushi Enomoto ${ }^{1}$, \\ Moriya Kikuchi ${ }^{4}$ and Seigou Kawaguchi ${ }^{1}$ \\ 1 Department of Organic Materials Science, Graduate School of Organic Materials Science, \\ Yamagata University, Jonan 4-3-16, Yonezawa 992-8510, Japan; ttc78981@st.yamagata-u.ac.jp (T.K.); \\ yamadasa007@gmail.com (M.Y.); monoceutical@yahoo.com (M.S.A.S.); kazushi.enomoto@riken.jp (K.E.); \\ skawagu@yz.yamagata-u.ac.jp (S.K.) \\ 2 Chair of Macromolecular Chemistry, Faculty of Natural Science II (Chemistry, Physics and Mathematics), \\ Martin-Luther University Halle-Wittenberg, Von-Danckelmann-Platz 4, D-06120 Halle (Saale), Germany; \\ wolfgang.binder@chemie.uni-halle.de \\ 3 Department of Chemistry and Chemical Engineering, Graduate School of Science and Engineering, \\ Yamagata University, Jonan 4-3-16, Yonezawa 992-8510, Japan; matsuda@yz.yamagata-u.ac.jp \\ 4 Department of Polymeric and Organic Materials Engineering, Faculty of Engineering, Yamagata University, \\ Jonan 4-3-16, Yonezawa 992-8510, Japan; m-kikuchi@yz.yamagata-u.ac.jp \\ * Correspondence: narumi@yz.yamagata-u.ac.jp; Tel.: +81-238-26-3829
}

Received: 29 May 2018; Accepted: 7 June 2018; Published: 8 June 2018

\begin{abstract}
Macrocyclic polymers present an important class of macromolecules, displaying the reduced radius of gyration or impossibility to entangle. A rare approach for their synthesis is the ring expansion-controlled radical "vinyl" polymerization, starting from a cyclic alkoxyamine. We here describe ring-expansion radical crossover reactions of cyclic alkoxyamines which run in parallel to chain-propagation reactions in the polymerization system. The radical crossover reactions extensively occurred at $105-125^{\circ} \mathrm{C}$, eventually producing high molecular weight polymers with multiple inherent dynamic covalent bonds (NOC bonds). A subsequent ring-contraction radical crossover reaction and the second ring-expansion radical crossover reaction are also described. The major products for the respective three stages were shown to possess cyclic morphologies by the molecular weight profiles and the residual ratios for the NOC bonds ( $\phi$ in \%). In particular, the high $\phi$ values ranging from ca. $80 \%$ to $98 \%$ were achieved for this cyclic alkoxyamine system. This result verifies the high availability of this system as a tool demonstrating the ring-expansion "vinyl" polymerization that allows them to produce macrocyclic polymers via a one-step vinyl polymerization.
\end{abstract}

Keywords: cyclic alkoxyamine; radical crossover reaction; ring-expansion reaction; ring-contraction reaction; ring-expansion vinyl polymerization; living radical polymerization; nitroxide-mediated controlled radical polymerization (NMP); macrocyclic polymer; cyclic topology

\section{Introduction}

Considerable attention has been payed to macromolecular architectures containing cyclic topologies [1-22], where the progress in the synthetic methods for cyclic polymers including ring-closing and/or ring-expansion methods has greatly contributed to the field [23-31]. However, ring-expansion "vinyl" polymerization as a tool to generate cyclic polymers via a one-step vinyl polymerization is relatively unexplored, including those based on the nitroxide-mediated controlled 
radical polymerization (NMP) [32-35], reversible addition fragmentation chain transfer (RAFT) polymerization [36], living cationic polymerization [37-40], and others [41]. We have recently developed intramolecularly-tethered alkoxyamine derivatives as cyclic NMP initiators [34,35], envisioning to achieve the synthesis of cyclic, vinyl-based polymers. In particular, styrene was polymerized with a cyclic NMP initiator, and the morphologies of the resulting high molecular weight polymers were discussed in terms of their radius of gyrations [35]. The reaction system is, however, not fully characterized primarily due to the occurrence of radical ring-crossover reactions, running in parallel to the conventional chain-growth propagation reactions, which in consequence lead to non-uniform polymer chain constructions. Thus, it is of great interest to exclude the vinyl polymerization reaction from the system and verify the "ring-expansion radical crossover reaction". We here report on methodology to understand the ring-crossover reactions taking place during the polymerization systems with cyclic NMP initiators. We expect that simplified information on this process is provided from the structural analyses of the products obtained by radical crossover reactions because the molecular weight profiles and spectroscopic data become clearer due to the absence of the large polymer units constructed by vinyl polymerizations. As displayed in Scheme 1, cyclic alkoxyamine $\mathbf{1}$ is heated in the absence of any polymerizable vinyl monomer at the appropriate temperatures where NMP-polymerization is normally taking place. The reactions of $\mathbf{1}$ are performed using diverse conditions and the structures of the resulting polymer 2 are characterized to clarify the temperature effects and time-dependent changes. In this paper, we further report the heating reaction of polymer $\mathbf{2}$ under highly diluted conditions using a solvent to demonstrate the "ring-contract radical crossover reaction". Finally, the capability for "the second ring-expansion radical crossover reaction" is explored to ensure the presence of cyclic morphologies in polymer 2.
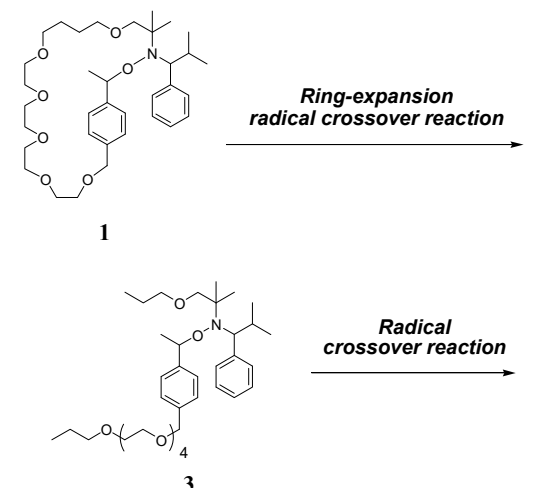

3

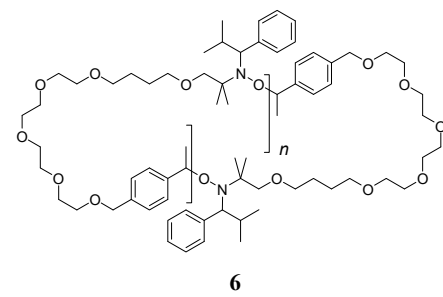

6

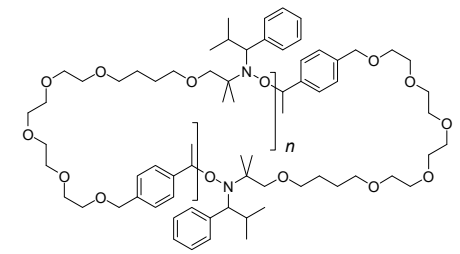

2

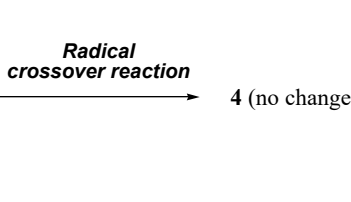

Second ring-expansion radical crossover reaction

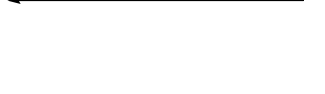

Scheme 1. Synthetic pathways of this paper starting from the heating reactions of cyclic and acyclic alkoxyamines together with the structures of the main products for the respective stages.

\section{Materials and Methods}

\subsection{Materials}

Cyclic alkoxyamine 1 was prepared according to the literature [35]. Other materials were obtained from commercial sources and used as received unless otherwise stated. 


\subsection{Methods}

The ${ }^{1} \mathrm{H}$ and ${ }^{13} \mathrm{C}$ NMR spectra were recorded using a JEOL JNM-ECX400 instrument (Tokyo, Japan). The size exclusion chromatography (SEC) analysis was performed using a system equipped with a Shodex GPC-System 21 (Tokyo, Japan), a SYSTEM INSTRUMENTS WP-03 Plus pump (Hachioji, Japan), a Shodex DEGAS degasser, Shodex KF-806L $(8.0 \mathrm{~mm} \times 300 \mathrm{~mm}$, average bead size: $10 \mu \mathrm{m}$, exclusion limit: $\left.2 \times 10^{4} \mathrm{~kg} \cdot \mathrm{mol}^{-1}\right), \mathrm{KF}-804 \mathrm{~L}(8.0 \mathrm{~mm} \times 300 \mathrm{~mm}$, average bead size: $7 \mu \mathrm{m}$, exclusion limit: $\left.4 \times 10^{3} \mathrm{~kg} \cdot \mathrm{mol}^{-1}\right), \mathrm{K}-803\left(8.0 \mathrm{~mm} \times 300 \mathrm{~mm}\right.$, average bead size: $6 \mu \mathrm{m}$, exclusion limit: $\left.70 \mathrm{~kg} \cdot \mathrm{mol}^{-1}\right)$ columns, a Shodex RI-71S, and a TOSOH UV-802 using (Tokyo, Japan) THF as the eluent at a flow rate of $1.0 \mathrm{~mL} \cdot \mathrm{min}^{-1}$ at $40{ }^{\circ} \mathrm{C}$. The weight average molecular weight $\left(M_{\mathrm{W}}\right)$, the molecular weight distribution $\left(M_{\mathrm{w}} / M_{\mathrm{n}}\right)$, and the molecular weight at the peak top $\left(M_{\mathrm{p}}\right)$ were determined by the RI based on linear PSt standards (Tosoh Co., Tokyo, Japan) with the $M_{\mathrm{W}} \mathrm{S}$ of $775,000,422,000,186,000$, $114,000,44,100,16,700,8300,5120,2360,870,500$, and 110 .

\subsection{Ring-Expansion Radical Crossover Reaction (Synthesis of 2)}

Cyclic alkoxyamine $\mathbf{1}(21 \mathrm{mg}, 35 \mathrm{~mol}$ ) was placed in a $2 \mathrm{~mL}$ dry glass ampule and then degassed in vacuo. After being flame-sealed under a vacuum, the ampule was allowed to stand at $115^{\circ} \mathrm{C}$ for $3 \mathrm{~h}$. The reaction was stopped by rapid cooling with liquid nitrogen to produce polymer $\mathbf{2}-\mathrm{V}$ as a pale yellow viscous liquid (recovered yield, $20 \mathrm{mg}$; 93\%). Data for 2-V: ${ }^{1} \mathrm{H}$ NMR (500 MHz, $\left.\mathrm{CDCl}_{3}\right)$ : $\delta 7.45-7.14(\mathrm{~m}$, phenyl- $\mathrm{H}), 4.90$ (m, CHON), $4.57\left(\mathrm{OCH}_{2}\right.$-phenyl), 3.64-2.31 (br, $\mathrm{OCH}_{2} \mathrm{CH}_{2} \mathrm{O}, \mathrm{OCH}_{2}\left(\mathrm{CH}_{2}\right)_{2} \mathrm{CH}_{2} \mathrm{O}, \mathrm{NCH}$, $\left.\mathrm{OCH}_{2}\left(\mathrm{CH}_{2}\right)_{2} \mathrm{CH}_{2} \mathrm{O}\right), \mathrm{OCH}_{2} \mathrm{C}\left(\mathrm{CH}_{3}\right)_{2} \mathrm{~N}$ and $\left.\mathrm{CH}\left(\mathrm{CH}_{3}\right)_{2}\right), 1.67-0.20$ (br, $\mathrm{CH}_{3} \mathrm{CH}\left(-\right.$ phenyl)O, $\mathrm{CH}\left(\mathrm{CH}_{3}\right)_{2}$ and $\left.\mathrm{NC}\left(\mathrm{CH}_{3}\right)_{2}\right) \cdot M_{\mathrm{w}}=38,000, M_{\mathrm{w}} / M_{\mathrm{n}}=24.8 . M_{\mathrm{p}}=58,400$.

\subsection{Ring-Contraction Radical Crossover Reaction (Synthesis of 5)}

A mixture of 2-V $(19 \mathrm{mg})$ and 1,3-dichlorobenzene $(8.6 \mathrm{~mL})$ was placed in a dry glass ampule with a magnetic stir bar and then degassed by five freeze-evacuate-thaw cycles. After being flame-sealed under a vacuum, the ampule was stirred at $115^{\circ} \mathrm{C}$ for $9 \mathrm{~h}$. The polymerization was stopped by rapid cooling with liquid nitrogen. The mixture was evaporated to dryness to give product $5-\mathrm{V}$ as a yellow oil (recovered yield, $14 \mathrm{mg} ; 77 \%)$. Data for 5-V: ${ }^{1} \mathrm{H}$ NMR $\left(500 \mathrm{MHz}, \mathrm{CDCl}_{3}\right): \delta 7.44-7.15(\mathrm{~m}$, phenyl- $\mathrm{H}), 4.91(\mathrm{~m}, \mathrm{CHON}), 4.57\left(\mathrm{OCH}_{2}\right.$-phenyl), 3.67-2.33 (m, $\mathrm{OCH}_{2} \mathrm{CH}_{2} \mathrm{O}, \mathrm{OCH}_{2}\left(\mathrm{CH}_{2}\right)_{2} \mathrm{CH}_{2} \mathrm{O}, \mathrm{NCH}$, $\mathrm{OCH}_{2}\left(\mathrm{CH}_{2}\right)_{2} \mathrm{CH}_{2} \mathrm{O}, \mathrm{OCH}_{2} \mathrm{C}\left(\mathrm{CH}_{3}\right)_{2} \mathrm{~N}$ and $\left.\mathrm{CH}\left(\mathrm{CH}_{3}\right)_{2}\right), 1.63-0.18\left(\mathrm{~m}, \mathrm{CH}_{3} \mathrm{CH}\left(-\right.\right.$ phenyl)O, $\mathrm{CH}\left(\mathrm{CH}_{3}\right)_{2}$ and $\left.\mathrm{NC}\left(\mathrm{CH}_{3}\right)_{2}\right) \cdot M_{\mathrm{W}}=690, M_{\mathrm{w}} / M_{\mathrm{n}}=1.87 \cdot M_{\mathrm{p}}=231$.

\subsection{Second Ring-Expansion Radical Crossover Reaction (Synthesis of 6)}

The same procedure as that for the synthesis of 2 was applied for $5-\mathrm{V}$ (14 mg) to give 6-V (recovered yield, $11 \mathrm{mg}$; 78\%) Data for 6-V: ${ }^{1} \mathrm{H}$ NMR $\left(500 \mathrm{MHz}, \mathrm{CDCl}_{3}\right)$ : $\delta 7.45-7.15(\mathrm{~m}$, phenyl-H), $4.90(\mathrm{~m}, \mathrm{CHON}), 4.55\left(\mathrm{OCH}_{2}\right.$-phenyl), 3.65-2.32 (m, $\mathrm{OCH}_{2} \mathrm{CH}_{2} \mathrm{O}, \mathrm{OCH}_{2}\left(\mathrm{CH}_{2}\right)_{2} \mathrm{CH}_{2} \mathrm{O}$, $\left.\mathrm{NCH}, \mathrm{OCH}_{2}\left(\mathrm{CH}_{2}\right)_{2} \mathrm{CH}_{2} \mathrm{O}, \mathrm{OCH}_{2} \mathrm{C}\left(\mathrm{CH}_{3}\right)_{2} \mathrm{~N}, \mathrm{CH}\left(\mathrm{CH}_{3}\right)_{2}\right), 1.61-0.20\left(\mathrm{~m}, \mathrm{CH}_{3} \mathrm{CH}\right.$ (-phenyl)O, $\mathrm{CH}\left(\mathrm{CH}_{3}\right)_{2}$ and $\left.\mathrm{NC}\left(\mathrm{CH}_{3}\right)_{2}\right) \cdot M_{\mathrm{w}}=13,500, M_{\mathrm{W}} / M_{\mathrm{n}}=6.59 \cdot \mathrm{M}_{\mathrm{p}}=14,700$.

\section{Results and Discussion}

\subsection{Ring-Expansion Radical Crossover Reaction}

\subsubsection{Temperature Effect}

Cyclic alkoxyamine $\mathbf{1}$ was heated in the bulk condition without any vinyl monomers (Scheme 1 ). The reactions were performed at diverse temperatures such as $105,115,125$, and $135^{\circ} \mathrm{C}$ for $12 \mathrm{~h}$ to afford products 2-I, 2-II, 2-III, and 2-IV, respectively (entries 1-4 in Table 1). Figure 1a shows size exclusion chromatography (SEC) traces of $\mathbf{1}$ and products $\mathbf{2 - I} \sim \mathbf{I V}$. The trace of $\mathbf{1}$ exhibited a sharp peak at the retention time (RT) of $32 \mathrm{~min}$. The traces of 2-I III are first described, which showed the broad 
peaks due to high molecular weight polymer species at the RTs ranging from 19 to 27 min together with the multiple peaks due to oligomeric species at the RTs ranging from 27 to $30 \mathrm{~min}$. The peaks attributable to monomeric species were observed at the RTs of 31 and $32 \mathrm{~min}$ as will be described later in the paper. Thus, the extensive occurrences of radical ring-crossover reactions were clearly revealed, which would be featured phenomena for alkoxyamine derivatives with cyclic morphologies.

Table 1. Conditions and results for the radical crossover reactions.

\begin{tabular}{|c|c|c|c|c|c|c|c|c|}
\hline Entry & Starting Material & Temp. $\left({ }^{\circ} \mathrm{C}\right)$ & Time (h) & Product Code & $M_{\mathrm{w}} 1$ & $M_{\mathrm{w}} / M_{\mathrm{n}}{ }^{1}$ & $M_{\mathrm{p}}{ }^{1}$ & $\phi^{2}(\%)$ \\
\hline 1 & 1 & 105 & 12 & 2-I & 42,800 & 18.1 & 57,100 & 93 \\
\hline 2 & 1 & 115 & 12 & 2-II & 29,600 & 11.0 & 24,900 & 90 \\
\hline 3 & 1 & 125 & 12 & 2-III & 13,600 & 7.04 & 12,400 & 74 \\
\hline 4 & 1 & 135 & 12 & 2-IV & 2930 & 3.33 & 446 & - \\
\hline 5 & 3 (control) & 115 & 12 & 4 & 506 & 1.06 & 426 & 90 \\
\hline 6 & 1 & 115 & 3 & $2-\mathrm{V}$ & 38,000 & 24.8 & 58,400 & 98 \\
\hline 7 & 1 & 115 & 6 & 2-VI & 26,600 & 11.3 & 28,600 & 92 \\
\hline $8(=2)$ & 1 & 115 & 12 & 2-VII (=2-II) & 29,600 & 11.0 & 24,900 & 90 \\
\hline 9 & 1 & 115 & 24 & 2-VIII & 20,300 & 8.5 & 19,300 & 82 \\
\hline 10 & 1 & 125 & 3 & 2-IX & 38,600 & 15.9 & 50,600 & 92 \\
\hline 11 & 1 & 125 & 6 & $2-X$ & 23,500 & 9.27 & 24,500 & 84 \\
\hline $12(=3)$ & 1 & 125 & 12 & $2-\mathrm{XI}(=2-\mathrm{III})$ & 13,600 & 7.04 & 12,400 & 74 \\
\hline 13 & 1 & 125 & 24 & 2-XII & 10,300 & 6.11 & 9940 & 64 \\
\hline
\end{tabular}

${ }^{1}$ Determined by SEC in THF based on the calibrations using linear PSt standards. ${ }^{2}$ Residual ratios for NOC bonds determined by ${ }^{1} \mathrm{H}$ NMR spectra.

The SEC measurement provided the weight average molecular weight $\left(M_{\mathrm{w}}\right)$ and the molecular weight distribution $\left(M_{\mathrm{w}} / M_{\mathrm{n}}\right)$ based on a calibration using linear PSt standards. As listed in Table 1, the $M_{\mathrm{W}}$ values ranged from 13,600 to 42,800 and $M_{\mathrm{W}} / M_{\mathrm{n}}$ values ranged from 7.04 to 18.1 for 2-I III (entries 1-3). The molecular weight at the peak top $\left(M_{\mathrm{p}}\right)$ would be the appropriate value to discuss the tendencies for this system showing multimodal SEC profiles. The $M_{\mathrm{p}}$ values for the main products were 57,100 for $\mathbf{2 - I}, 24,900$ for 2 -II, and 12,400 for 2-III. As the molecular weight of $\mathbf{1}$ is 602 , the respective $M_{p}$ values corresponded to the 65-, 30-, and 15-mers. However, this estimation is very rough because the $M_{p}$ values were linear PSt-based apparent ones, whereas again supports the extensive occurrences of radical ring-crossover reactions. The $M_{p}$ values tended to decrease as the reaction temperatures increased, as shown in Figure 1a. The 2-IV system (Figure 1a and entry 4 in Table 1) showed a different feature as compared to the others in which the major peak was observed in the low molecular weight regions at the RTs ranging from 30 to $32 \mathrm{~min}$. We previously reported that acyclic alkoxyamine $\mathbf{3}$ (Scheme 1) was prepared as a linear counterpart of $\mathbf{1}$ and used as an initiator for the polymerization of styrene [36]. In this study, we newly performed the heating reaction of 3 to give product 4 (Entry 5 in Table 1). Figure 1a shows the SEC traces of 3 and 4 in which both exhibited sharp peaks at the RT of $31 \mathrm{~min}$. Hence, no significant change was observed for the molecular weight profiles for the $\mathbf{3}$ system. It should be stated that the result that the RT of $\mathbf{3}(31 \mathrm{~min})$ is shorter than that of $\mathbf{1}$ (32 $\mathrm{min}$ ) is rationalized by a compact cyclic structure of $\mathbf{1}$. Furthermore, this RT difference is advantageous for the mechanism clarification. For the 2-I IV systems, the peaks were observed at the RTs of 31 and $32 \mathrm{~min}$ (Figure 1a) and we assigned the respective peaks to those for the linear (cleaved) unimer and the cyclic (tethered) one.

Figure 2 shows the ${ }^{1} \mathrm{H}$ NMR spectra of $\mathbf{1}$ and 2-I IV. The characteristic signal due to the methine proton in the alkoxyamine moieties $(\mathrm{a}, 1 \mathrm{H})$ appeared at $4.9 \mathrm{ppm}$ for the spectrum of 1 . The fact that the corresponding signals were observed for 2-I 2-III suggested the presence of dynamic covalent bonds (NOC bonds) even after the reactions. The signal due to the methylene protons in the benzyl position $(\mathrm{b}, 2 \mathrm{H})$ was also observed at $4.5 \mathrm{ppm}$ for the spectrum of 1 . We determined the $I_{\mathrm{a}} / I_{\mathrm{b}}$ values where the $I_{\mathrm{a}}$ and $I_{\mathrm{b}}$ denote the integrations (peak areas) of the signals (a) and (b), respectively. The $I_{\mathrm{a}} / I_{\mathrm{b}}$ values were $1.0 / 2.0$ for $1,0.93 / 2.0$ for 2-I, $0.90 / 2.0$ for 2 -II, and $0.74 / 2.0$ for 2 -III. The $I_{\mathrm{a}} / I_{\mathrm{b}}$ values would be equivalent to the residual ratios for NOC bonds ( $\phi$ in $\%$ ). The $\phi$ values were $93 \%$ for $2-I, 90 \%$ for $2-I I$, and $74 \%$ for 2-III as listed in entries 1-3 in Table 1. Thus, a large amount of NOC bonds remained in the products obtained at the reaction temperatures of $105-125^{\circ} \mathrm{C}$. On the other hand, for 2-IV obtained at the temperature of $135^{\circ} \mathrm{C}$, the occurrences of side reactions were suggested by the NMR 
analysis. The signals (x) at $6.7 \mathrm{ppm},(\mathrm{y})$ at $5.7 \mathrm{ppm}$, and (z) at $5.2 \mathrm{ppm}$ appeared for the spectrum of 2-IV (Figure 2). As judged from the chemical shifts and coupling constants, the signals were assignable to the vinyl protons formed as a result of irreversible heterolysis (disproportionation) of the NOC bonds. The similar signals were also observed for 2-III (Figure 2), whereas their intensities were very weak. We reached the conclusion that "ring-expansion radical crossover reaction" extensively occurred at $105-125^{\circ} \mathrm{C}$, eventually producing high molecular weight polymers with inherent multiple NOC bonds as shown in Scheme 1.

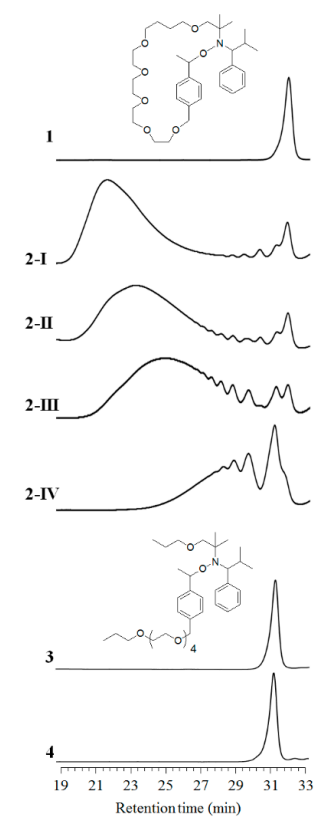

(a)

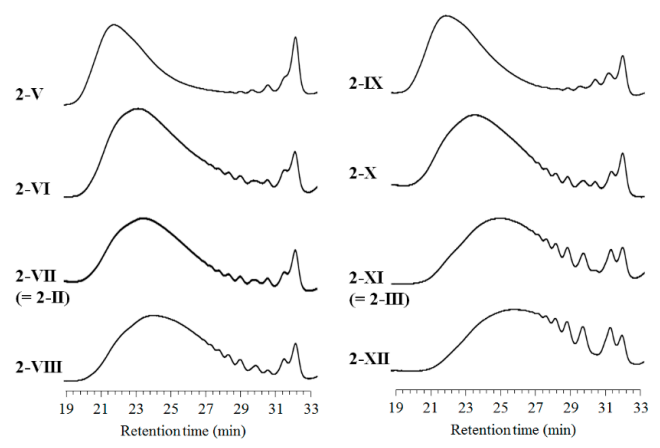

(b)

Figure 1. SEC traces of (a) 1, 2-I IV, 3, and 4 and (b) 2-V $\sim$ VIII and 2-IX $\sim$ XII.
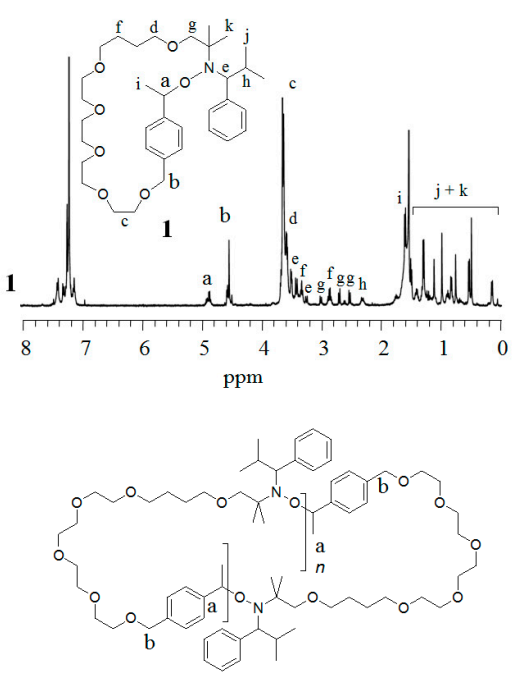

2

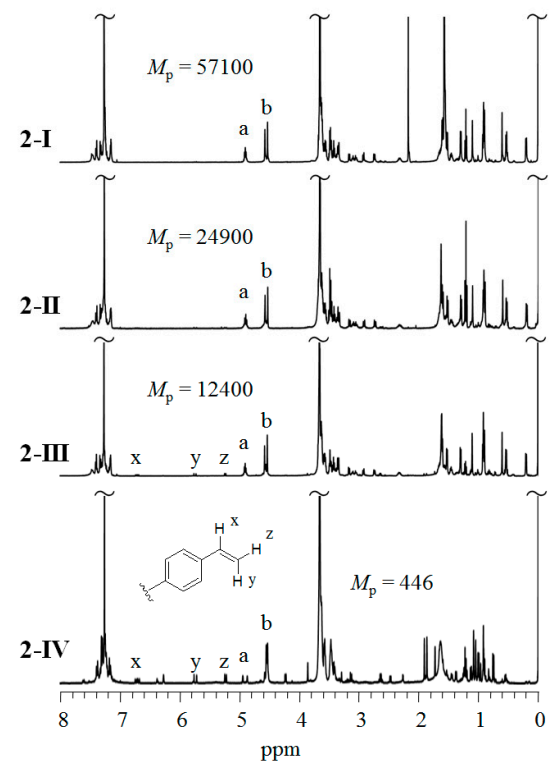

Figure 2. ${ }^{1} \mathrm{H}$ NMR spectra of $\mathbf{1}$ and $\mathbf{2}-\mathbf{I} \sim \mathbf{I V}$. 


\subsubsection{Time-Dependent Changes}

The reactions of 1 were performed for different times such as 3, 6, 12, and $24 \mathrm{~h}$ to elucidate time-dependent changes. Figure $1 \mathrm{~b}$ shows the SEC traces of the products $\mathbf{2}-\mathrm{V} \sim$ VIII and 2-IX $\sim$ XII, which were obtained for the 115 and $125^{\circ} \mathrm{C}$ systems, respectively. Table 1 summarizes the results for the characterizations of 2-V $\sim$ VIII (Entries 6-9) and 2-IX XII (Entries 10-13). The $M_{\mathrm{W}}$ values ranged from 10,300 to 38,600 . The $M_{\mathrm{w}} / M_{\mathrm{n}}$ values were between 6.11 and 24.8 . The $M_{\mathrm{p}}$ values ranged from 9940 to 58,400 . Thus, high molecular weight polymers were formed as a result of the radical ring-crossover reactions. The $\phi$ values varied from $64 \%$ to $98 \%$. In general, both the $M_{p}$ and $\phi$ values were high for the systems at $115{ }^{\circ} \mathrm{C}$ as compared to those at $125^{\circ} \mathrm{C}$ (Table 1); for example, the highest values were $M_{p}=58,400$ and $\phi=98 \%$ for $2-\mathrm{V}$. It should be noticed that the SEC trace showed the peaks at the RT of $32 \mathrm{~min}$ (Figure 1b). Thus, 2-V XII include considerable amounts of cyclic (tethered) unimers. The traces also exhibited the peak or shoulder attributable to linear (cleaved) unimers at the RT of $31 \mathrm{~min}$. As judged from the peak intensities, the cyclic unimers were preferentially formed over the linear ones throughout the reactions for the $115^{\circ} \mathrm{C}$ system, while the formation of the linear ones increased with the increasing reaction times for the $125^{\circ} \mathrm{C}$ system. This result supported that $115^{\circ} \mathrm{C}$ is a suitable temperature in the view point of preventing ring cleavages.

\subsection{Ring-Contraction Radical Crossover Reaction}

In order to ensure the performance of the cyclic alkoxyamine system, we exploited the "ring-contraction radical crossover reaction" (Scheme 1). Polymer 2-V with the $M_{\mathrm{p}}$ for the main peak of 58,400 was heated at $115^{\circ} \mathrm{C}$ in 1,3-dichlorobenzene under a highly diluted condition such as $0.003 \mathrm{M}$ (Entry 14 in Table 2). The reaction for $9 \mathrm{~h}$ produced a product 5-V. Figure 3 shows the SEC trace of 5-V with the $M_{\mathrm{w}}\left(M_{\mathrm{w}} / M_{\mathrm{n}}\right)$ of $690(1.87)$ and the $M_{\mathrm{p}}$ for the main peak of 231 . The trace exhibited multimodal peaks only in the low molecular weight regions with the RTs ranging from 29 to $32 \mathrm{~min}$ and the main peak with the RT of $32 \mathrm{~min}$ was assigned to a cyclic (tethered) unimer. The NOC bonds remained with the high $\phi$ value of $90 \%$. Similar results for these ring-expansion/contraction phenomena were previously reported by Otsuka and coworkers [42]. They described the results using phrases "polymerization of macrocyclic alkoxyamine" and "depolymerization of poly(alkoxyamine)" in the paper, where they have studied the dynamic covalent polymer systems based on the 2,2,6,6-tetramethylpiperidine-1-oxyl (TEMPO) as persistent radicals.

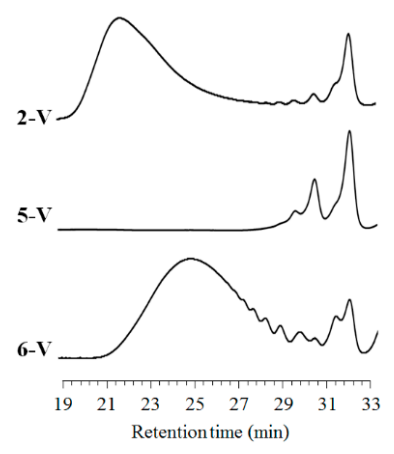

Figure 3. SEC traces of $2-\mathrm{V}, 5-\mathrm{V}$, and $6-\mathrm{V}$.

Table 2. Condition and results for the ring-contraction radical crossover reaction and subsequent second ring-expansion radical crossover reaction.

\begin{tabular}{ccccccccc}
\hline Entry & Starting Material & Temp. $\left({ }^{\circ} \mathbf{C}\right)$ & Time (h) & Product Code & $\boldsymbol{M}_{\mathbf{w}}{ }^{\mathbf{1}}$ & $\boldsymbol{M}_{\mathbf{w}} / \boldsymbol{M}_{\mathbf{n}}{ }^{\mathbf{1}}$ & $\boldsymbol{M}_{\mathbf{p}}{ }^{\mathbf{1}}$ & $\boldsymbol{\phi}^{\mathbf{2}}(\%)$ \\
\hline 14 & $\mathbf{2 - V}$ & 115 & 9 & $\mathbf{5 - V}$ & 690 & 1.87 & 231 & 90 \\
\hline 15 & $\mathbf{5 - V}$ & 115 & 3 & $\mathbf{6 - V}$ & 13,500 & 6.59 & 14,700 & 84 \\
\hline
\end{tabular}

1 Determined by SEC in THF based on the calibrations using linear PSt standards. ${ }^{2}$ Residual ratios for NOC bonds determined by ${ }^{1} \mathrm{H}$ NMR spectra. 
We here summarize radical crossover reactions for the cyclic systems, which significantly differs from those for the acyclic system. Scheme 2 shows the radical reactions starting from two kinds of alkoxyamines in this study. No change has been brought by the intermolecular radical crossover reactions for the acyclic system in terms of molecular weights and morphologies as experimentally shown in this study. The applications based on the radical exchange reactions have been discussed elsewhere [43-46]. On the other hand, for the cyclic system, the inherent dynamic covalent bond (NOC bond) takes place on a homolytic cleavage to generate a reactive benzyl radical and a persistent nitroxide radical (Scheme 2). A subsequent recombination reaction provides opportunities for the NOC bond exchange. The ring-expansion reactions proceed when the intermolecular recombination reactions occur, in which a prime driving force would be a decrease in the ring strain, resulting in the large increase in the molecular weights. This phenomenon is attributable to an inherent NOC bond in a cycle or multiple NOC bonds in a linear chain. The result of this study is originally due to the inherent NOC bond in a cycle because 1 possesses only one dynamic covalent bond. Under highly diluted conditions where the intermolecular reaction would not be accepted, intramolecular recombination would proceed, eventually returning to the original cyclic unimer.

\subsection{Second Ring-Expansion Radical Crossover Reaction}

When taking into account the above-mentioned mechanisms, the result that the main components in $5-\mathrm{V}$ was not a cleaved unimer but a tethered one with the high $\phi$ value of $90 \%$ motivated us to demonstrate the "second ring-expansion radical crossover reaction". We performed the reaction of 5-V at $115{ }^{\circ} \mathrm{C}$ for $3 \mathrm{~h}$ in the bulk condition to produce products 6-V (Entry 15 in Table 2). Figure 3 shows the SEC trace of 6-V with the $M_{\mathrm{W}}\left(M_{\mathrm{W}} / M_{\mathrm{n}}\right)$ of $13,500(6.59)$ and the $M_{\mathrm{p}}$ for the main peak of 14,700 . The trace again showed the broad peaks due to high molecular weight polymer species at the RTs ranging from 21 to $27 \mathrm{~min}$ together with the multiple peaks due to the oligomeric species at the RTs ranging from 27 to $30 \mathrm{~min}$. The monomeric species were also observed at the RTs of 31 and $32 \mathrm{~min}$. Therefore, the featured reactions due to the "cyclic" alkoxyamine system again extensively occurred to produce $6-\mathrm{V}$ with a high $\phi$ value of $84 \%$. This result strongly supports that $2-\mathrm{V}$ (and also $5-\mathrm{V}$ ) contains polymeric species with cyclic morphologies.

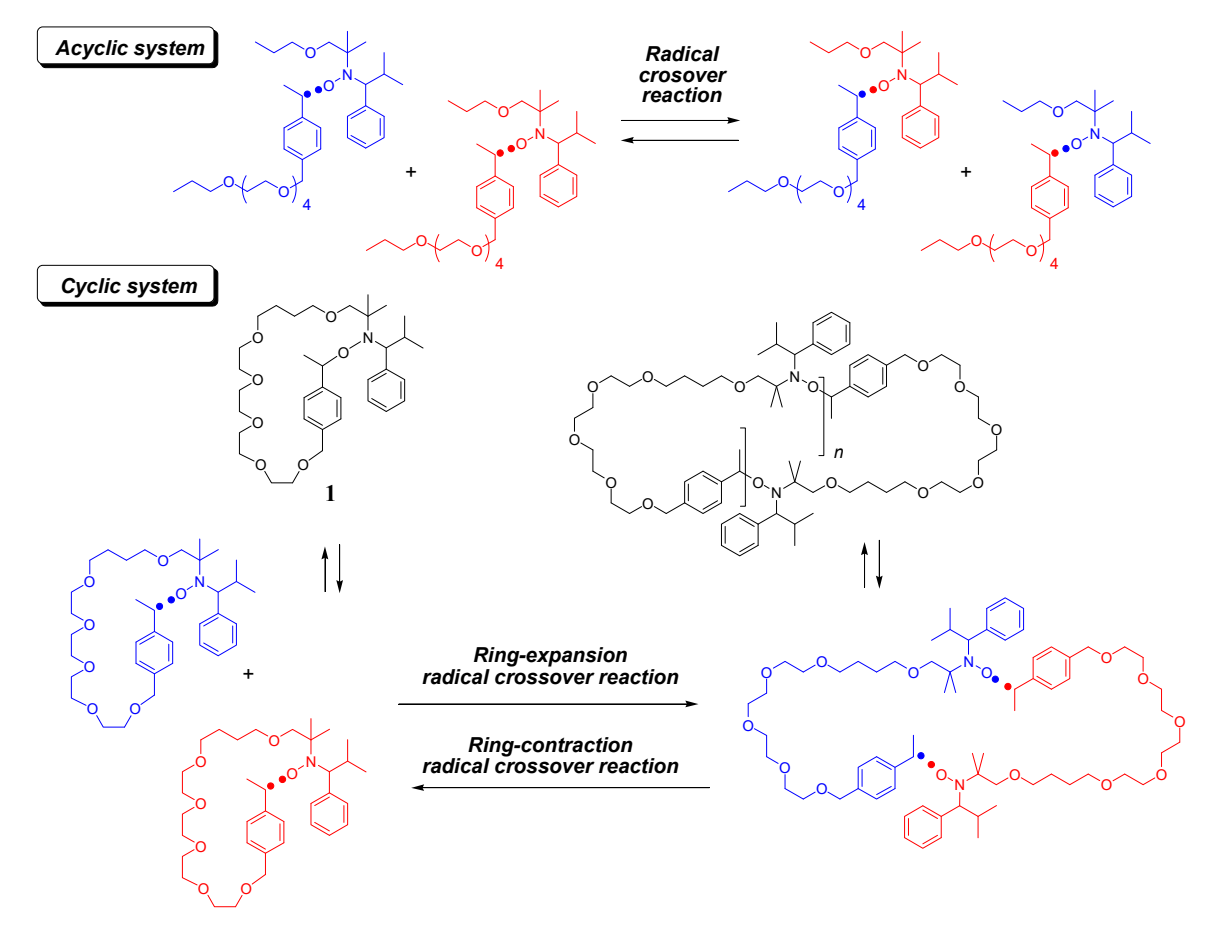

Scheme 2. Radical crossover reactions for the acyclic and cyclic systems. 


\section{Conclusions}

A series of radical ring-crossover reactions were verified using the strategy that cyclic alkoxyamine and their reaction products were heated at the NMP temperatures without any vinyl monomers. The extensive occurrences of "ring-expansion radical crossover reaction" were clearly revealed, which would be featured phenomena for alkoxyamine derivatives with cyclic morphologies, eventually producing high molecular weight polymers with inherent dynamic covalent bonds. The "ring-contract radical crossover reaction" was performed for the resulting polymer and subsequently the "second ring-expansion radical crossover reaction" was demonstrated, which strongly supported the presence of high amounts of cyclic morphologies throughout the series of reactions.

Author Contributions: A.N., W.H.B. and S.K. proposed the idea of the project and wrote the paper; A.N., T.K., M.Y. and M.S.A.S. conceived and designed the experiments; T.K. carried out the experiments and measurements; K.M. contributed materials; K.E. and M.K. performed the measurements and analyzed the data. All authors contributed to the discussions and finalization of the manuscript.

Acknowledgments: This study was partly supported by JSPS KAKENHI Grant Number 16K05786.

Conflicts of Interest: The authors declare no conflict of interest.

\section{References}

1. Oike, H.; Hamada, M.; Eguchi, S.; Danda, Y.; Tezuka, Y. Novel synthesis of single- and double-cyclic polystyrenes by electrostatic self-assembly and covalent fixation with telechelics having cyclic ammonium salt groups. Macromolecules 2001, 34, 2776-2782. [CrossRef]

2. Bielawski, C.W.; Benitez, D.; Grubbs, R.H. An “endless" route to cyclic polymers. Science 2002, 297, $2041-2044$. [CrossRef] [PubMed]

3. Bielawski, C.W.; Benitez, D.; Grubbs, R.H. Synthesis of Cyclic Polybutadiene via Ring-Opening Metathesis Polymerization: The Importance of Removing Trace Linear Contaminants. J. Am. Chem. Soc. 2003, 125, 8424-8425. [CrossRef] [PubMed]

4. Culkin, D.A.; Jeong, W.H.; Csihony, S.; Gomez, E.D.; Balsara, N.R.; Hedrick, J.L.; Waymouth, R.M. Zwitterionic polymerization of lactide to cyclic poly(lactide) by using $N$-heterocyclic carbene organocatalysts. Angew. Chem. Int. Ed. 2007, 46, 2627-2630. [CrossRef] [PubMed]

5. Schappacher, M.; Deffieux, A. Atomic Force Microscopy Imaging and Dilute Solution Properties of Cyclic and Linear Polystyrene Combs. J. Am. Chem. Soc. 2008, 130, 14684-14689. [CrossRef] [PubMed]

6. Schappacher, M.; Deffieux, A. Synthesis of Macrocyclic Copolymer Brushes and Their Self-Assembly into Supramolecular Tubes. Science 2008, 319, 1512-1515. [CrossRef] [PubMed]

7. Jeong, W.; Shin, E.J.; Culkin, D.A.; Hedrick, J.L.; Waymouth, R.M. Zwitterionic Polymerization: A Kinetic Strategy for the Controlled Synthesis of Cyclic Polylactide. J. Am. Chem. Soc. 2009, 131, 4884-4891. [CrossRef] [PubMed]

8. Xia, Y.; Boydston, A.J.; Grubbs, R.H. Synthesis and Direct Imaging of Ultrahigh Molecular Weight Cyclic Brush Polymers. Angew. Chem. Int. Ed. 2011, 50, 5882-5885. [CrossRef] [PubMed]

9. Lahasky, S.H.; Serem, W.K.; Guo, L.; Garno, J.C.; Zhang, D.H. Synthesis and Characterization of Cyclic Brush-Like Polymers by N-Heterocyclic Carbene-Mediated Zwitterionic Polymerization of N-Propargyl $\mathrm{N}$-Carboxyanhydride and the Grafting-to Approach. Macromolecules 2011, 44, 9063-9074. [CrossRef]

10. Zhang, K.; Lackey, M.A.; Wu, Y.; Tew, G.N. Universal Cyclic Polymer Templates. J. Am. Chem. Soc. 2011, 133, 6906-6909. [CrossRef] [PubMed]

11. Zhang, K.; Tew, G.N. Cyclic Brush Polymers by Combining Ring-Expansion Metathesis Polymerization and the "Grafting from" Technique. ACS Macro Lett. 2012, 1, 574-579. [CrossRef]

12. Wei, H.; Chu, D.S.H.; Zhao, J.L.; Pahang, J.A.; Pun, S.H. Synthesis and Evaluation of Cyclic Cationic Polymers for Nucleic Acid Delivery. ACS Macro Lett. 2013, 2, 1047-1050. [CrossRef] [PubMed]

13. Zhang, K.; Zha, Y.P.; Peng, B.; Chen, Y.M.; Tew, G.N. Metallo-Supramolecular Cyclic Polymers. J. Am. Chem. Soc. 2013, 135, 15994-15997. [CrossRef] [PubMed]

14. Danial, M.; Tran, C.M.N.; Jolliffe, K.A.; Perrier, S. Thermal Gating in Lipid Membranes Using Thermoresponsive Cyclic Peptide-Polymer Conjugates. J. Am. Chem. Soc. 2014, 136, 8018-8026. [CrossRef] [PubMed] 
15. Zhang, K.; Tew, G.N. Cyclic polymers as a building block for cyclic brush polymers and gels. React. Funct. Polym. 2014, 80, 40-47. [CrossRef]

16. Cortez, M.A.; Godbey, W.T.; Fang, Y.L.; Payne, M.E.; Cafferty, B.J.; Kosakowska, K.A.; Grayson, S.M. The Synthesis of Cyclic Poly(ethylene imine) and Exact Linear Analogues: An Evaluation of Gene Delivery Comparing Polymer Architectures. J. Am. Chem. Soc. 2015, 137, 6541-6549. [CrossRef] [PubMed]

17. Kimura, A.; Hasegawa, T.; Yamamoto, T.; Matsumoto, H.; Tezuka, Y. ESA-CF Synthesis of Linear and Cyclic Polymers Having Densely Appended Perylene Units and Topology Effects on Their Thin-Film Electron Mobility. Macromolecules 2016, 49, 5831-5840. [CrossRef]

18. Roland, C.D.; Li, H.; Abboud, K.A.; Wagener, K.B.; Veige, A.S. Cyclic polymers from alkynes. Nat. Chem. 2016, 8, 791-796. [CrossRef] [PubMed]

19. Zhang, S.S.; Yin, L.; Zhang, W.; Zhang, Z.B.; Zhu, X.L. Synthesis of diverse cyclic-brush polymers with cyclic polystyrene as a universal template via a grafting-from approach. Polym. Chem. 2016, 7, $2112-2120$. [CrossRef]

20. Zhang, H.C.; Wu, W.T.; Zhao, X.Q.; Zhao, Y.L. Synthesis and Thermoresponsive Behaviors of Thermo-, pH-, $\mathrm{CO}_{2}$ - and Oxidation-Responsive Linear and Cyclic Graft Copolymers. Macromolecules 2017, 50, 3411-3423. [CrossRef]

21. Xiao, L.F.; Qu, L.; Zhu, W.; Wu, Y.; Liu, Z.P.; Zhang, K. Donut-Shaped Nanoparticles Templated by Cyclic Bottlebrush Polymers. Macromolecules 2017, 50, 6762-6770. [CrossRef]

22. Honda, S.; Yamamoto, T.; Tezuka, Y. Tuneable enhancement of the salt and thermal stability of polymeric micelles by cyclized amphiphiles. Nat. Commun. 2013, 4, 1574. [CrossRef] [PubMed]

23. Eugene, D.M.; Grayson, S.M. Efficient Preparation of Cyclic Poly(methyl acrylate)-block-poly(styrene) by Combination of Atom Transfer Radical Polymerization and Click Cyclization. Macromolecules 2008, 41, 5082-5084. [CrossRef]

24. Laurent, B.A.; Grayson, S.M. Synthetic approaches for the preparation of cyclic polymers. Chem. Soc. Rev. 2009, 38, 2202-2213. [CrossRef] [PubMed]

25. Laurent, B.A.; Grayson, S.M. Synthesis of Cyclic Dendronized Polymers via Divergent "Graft-from" and Convergent Click "Graft-to" Routes: Preparation of Modular Toroidal Macromolecules. J. Am. Chem. Soc. 2011, 133, 13421-13429. [CrossRef] [PubMed]

26. Yamamoto, T.; Tezuka, Y. Topological polymer chemistry: A cyclic approach toward novel polymer properties and functions. Polym. Chem. 2011, 2, 1930-1941. [CrossRef]

27. Brown, H.A.; Waymouth, R.M. Zwitterionic Ring-Opening Polymerization for the Synthesis of High Molecular Weight Cyclic Polymers. Acc. Chem. Res. 2013, 46, 2585-2596. [CrossRef] [PubMed]

28. Yamamoto, T. Synthesis of cyclic polymers and topology effects on their diffusion and thermal properties. Polym. J. 2013, 45, 711-717. [CrossRef]

29. Josse, T.; De Winter, J.; Gerbaux, P.; Coulembier, O. Cyclic Polymers by Ring-Closure Strategies. Angew. Chem. Int. Ed. 2016, 55, 13944-13958. [CrossRef] [PubMed]

30. Tu, X.Y.; Liu, M.Z.; Wei, H. Recent Progress on Cyclic Polymers: Synthesis, Bioproperties, and Biomedical Applications. J. Polym. Sci. Part A Polym. Chem. 2016, 54, 1447-1458. [CrossRef]

31. Chang, Y.A.; Waymouth, R.M. Recent Progress on the Synthesis of Cyclic Polymers via Ring-Expansion Strategies. J. Polym. Sci. Part A Polym. Chem. 2017, 55, 2892-2902. [CrossRef]

32. Ruehl, J.; Ningnuek, N.; Thongpaisanwong, T.; Braslau, R. Cyclic Alkoxyamines for Nitroxide-Mediated Radical Polymerization. J. Polym. Sci. Part A Polym. Chem. 2008, 46, 8049-8069. [CrossRef]

33. Nicolaÿ, R.; Matyjaszewski, K. Synthesis of Cyclic (Co)polymers by Atom Transfer Radical Cross-Coupling and Ring Expansion by Nitroxide-Mediated Polymerization. Macromolecules 2011, 44, 240-247. [CrossRef]

34. Narumi, A.; Zeidler, S.; Barqawi, H.; Enders, C.; Binder, W.H. Cyclic Alkoxyamine-Initiator Tethered by Azide/Alkyne-“Click"-Chemistry Enabling Ring-Expansion Vinyl Polymerization Providing Macrocyclic Polymers. J. Polym. Sci. Part A Polym. Chem. 2010, 48, 3402-3416. [CrossRef]

35. Narumi, A.; Hasegawa, S.; Yanagisawa, R.; Tomiyama, M.; Yamada, M.; Binder, W.H.; Kikuchi, M.; Kawaguchi, S. Ring expansion-controlled radical polymerization: Synthesis of cyclic polymers and ring component quantification based on SEC-MALS analysis. React. Funct. Polym. 2016, 104, 1-8. [CrossRef]

36. Bunha, A.; Cao, P.F.; Mangadlao, J.D.; Advincula, R.C. Cyclic poly(vinylcarbazole) via ring-expansion polymerization-RAFT (REP-RAFT). React. Funct. Polym. 2014, 80, 33-39. [CrossRef] 
37. Kammiyada, H.; Konishi, A.; Ouchi, M.; Sawamoto, M. Ring-Expansion Living Cationic Polymerization via Reversible Activation of a Hemiacetal Ester Bond. ACS Macro Lett. 2013, 2, 531-534. [CrossRef]

38. Ouchi, M.; Kammiyada, H.; Sawamoto, M. Ring-expansion cationic polymerization of vinyl ethers. Polym. Chem. 2017, 8, 4970-4977. [CrossRef]

39. Kammiyada, H.; Ouchi, M.; Sawamoto, M. A Study on Physical Properties of Cyclic Poly(vinyl ether)s Synthesized via Ring-Expansion Cationic Polymerization. Macromolecules 2017, 50, 841-848. [CrossRef]

40. Kammiyada, H.; Ouchi, M.; Sawamoto, M. Expanding Vinyl Ether Monomer Repertoire for Ring-Expansion Cationic Polymerization: Various Cyclic Polymers with Tailored Pendant Groups. J. Polym. Sci. Part A Polym. Chem. 2017, 55, 3082-3089. [CrossRef]

41. He, T.; Zheng, G.H.; Pan, C.Y. Synthesis of cyclic polymers and block copolymers by monomer insertion into cyclic initiator by a radical mechanism. Macromolecules 2003, 36, 5960-5966. [CrossRef]

42. Yamaguchi, G.; Higaki, Y.; Otsuka, H.; Takahara, A. Reversible Radical Ring-Crossover Polymerization of an Alkoxyamine-Containing Dynamic Covalent Macrocycle. Macromolecules 2005, 38, 6316-6320. [CrossRef]

43. Harth, E.; Hawker, C.J.; Fan, W.; Waymouth, R.M. Chain end functionalization in nitroxide-mediated "Living" free radical polymerizations. Macromolecules 2001, 34, 3856-3862. [CrossRef]

44. Otsuka, H.; Aotani, K.; Higaki, Y.; Takahara, A. A dynamic (reversible) covalent polymer: Radical crossover behaviour of TEMPO-containing poly(alkoxyamine ester)s. Chem. Commun. 2002, 23, 2838-2839. [CrossRef]

45. Otsuka, H.; Aotani, K.; Higaki, Y.; Takahara, A. Polymer scrambling: Macromolecular radical crossover reaction between the main chains of alkoxyamine-based dynamic covalent polymers. J. Am. Chem. Soc. 2003, 125, 4064-4065. [CrossRef] [PubMed]

46. Jhaveri, S.B.; Beinhoff, M.; Hawker, C.J.; Carter, K.R.; Sogah, D.Y. Chain-end functionalized nanopatterned polymer brushes grown via in situ nitroxide free radical exchange. ACS Nano 2008, 2, 719-727. [CrossRef] [PubMed]

(C) 2018 by the authors. Licensee MDPI, Basel, Switzerland. This article is an open access article distributed under the terms and conditions of the Creative Commons Attribution (CC BY) license (http:// creativecommons.org/licenses/by/4.0/). 